\title{
ACTH4-10, Substance P, and Dizolcipine (MK-801) Accelerate Functional Recovery After Hemilabyrinthectomy in Goldfish
}

\author{
R. Mattioli, ${ }^{1 \dagger}$ J.P. Huston, ${ }^{2}$ and R.E. Spieler ${ }^{3}$ \\ ${ }^{1}$ Laboratory of Neuroscience, Department of Physical Therapy, Center for Biological and \\ Health Sciences, Universidade Federal de São Carlos, Brazil \\ ${ }^{2}$ Institute of Physiological Psychology, and Center for Biological and Medical Research, \\ University of Düsseldorf, Germany \\ ${ }^{3}$ Oceanographic Center, Nova Southeastern University, Dania, Florida, U.S.A.
}

\begin{abstract}
SUMMARY
In this study, we evaluated the goldfish model of hemilabyrinthectomy for investigating potential recovery-promoting drugs. In this lesion model, the unilateral removal of the labyrinth induces a postural imbalance in response to light (Dorsal Light Reflex), from which the animals can recover over time. The behavioral effects of two neuropeptides were tested-namely, of substance $P$ and ACTH4-10, both of which are known to promote functional recovery in several other lesion models. Furthermore, the effect of MK801, an antagonist of the glutamatergic NMDAreceptor subtype, was tested because this substance has also been shown to exert a neuroprotective effect. After lesion of the right labyrinth, the animals $(n=12)$ were treated intraperitoneally daily either with vehicle $(n=12)$, substance $P(n=11)$, ACTH4-10 $(n=12)$, or MK$801(n=12)$. Another group $(n=11)$, which served as a non-lesion control, did not receive hemilabyrinthectomy or systemic injections. The lesion group, treated post-operatively with vehicle,
\end{abstract}

did not recover from the postural deviation over the 24-d testing period. In contrast, all three test substances accelerated the functional recovery after unilateral labyrinthectomy. The decrease of the dorsal light reflex persisted even after cessation of drug treatment after $20 \mathrm{~d}$. The results indicate that using the dorsal light reflex in the model of hemilabyrinthectomy in goldfish provides a useful approach to studying the ability of potential new neurotrophic or neuroprotective drugs to promote functional recovery.

\section{KEYWORDS}

goldfish, MK-801, learning, Substance P, ACTH410 , functional recovery

\section{INTRODUCTION}

Hemilabyrinthectomy is a lesion model that has the important characteristic of lesioning the CNS without directly damaging tissue in the brain.

\footnotetext{
${ }^{\dagger}$ Corresponding author:

Laboratório de Neurosciências, Defisio, CCBS

Universidade Federal de São Carlos. Via Washington Luís, Km 235

CEP 13565-905-São Carlos-SP-Brasil

fax: +55-16-271-2081

e-mail: mattioli@power.ufscar.br
} 
The main behavioral consequence of this unilateral vestibular removal is a postural imbalance from which the animals can recover over time. Therefore, this model has been used in various species to study functional recovery and its possible physiological determinants (Schaefer \& Meyer, 1974; Dieringer, 1995; Deliagina, 1997; Vidal et al., 1998).

In goldfish, behavioral deficits and potential recovery after hemilabyrinthectomy can elegantly be studied by measuring the dorsal light reflex (DLR) (Ott \& Platt, 1988a; 1988b): When illuminated from one side, non-lesioned fish slightly tilt toward the light source, which indicates a role of vision in postural maintenance. Vestibular-lesioned fish, on the other hand, tilt very strongly toward the light, and some of them even align themselves fully with the light, indicating the loss of influence of the gravitational component on postural maintenance. With time after lesion, the degree of light-induced tilt can decrease, which is taken as the index of functional recovery. Apparently, after the loss of vestibular input, fish initially adjust posture, mainly using the visual system, whereas during the development of functional recovery, the impact of the gravitational component gradually increases again. Such recovery after hemilabyrinthectomy is thought to be due to compensatory mechanisms, including the following:

- bilateral adjustments in the activity of vestibular nuclei (Flohr \& Beinhold, 1981; Sans et al., 1997),

- modulation of the lesion side via commissural interconnections (Dieringer \& Precht, 1979),

- cerebellar input to the vestibular neurons (Dieringer \& Precht, 1979), and

- neurochemical modulation via cholinergic systems (Beinhold \& Flohr, 1980).

The lesion- and stimulus-dependent postural deficit and its potential to recover after hemilabyrinthectomy in goldfish might be useful for investigating the effectiveness of drugs for therapeutic means.
To test this hypothesis, we used two neuropeptidesnamely, substance $\mathrm{P}$ (SP) and the adrenocorticotropic hormone ACTH4-10, which have been shown to promote functional recovery and to have neurotrophic and/or neuroprotective effects in other species. With respect to the neurokinin SP, this substance is known to be present in the brain of mammals and fish (Schaefer \& Meyer, 1974) to promote functional recovery after brain lesions (Mattioli et al., 1992; Bannon et al., 1995) and to act in a neurotrophic and neuroprotective way (Jonsson \& Hallman, 1982; Iwasaki et al., 1989; Kowall et al., 1991; Mattioli et al., 1992; Nikolaus et al., 1999). ACTH4-10 can also accelerate recovery after hemilabyrithectomy in frogs (Flohr \& Lüneburg, 1982) and monkeys (Igarashi et al., 1985) and after lesions of the CNS (Antonawich et al., 1993; for review see van Rijzingen et al., 1996). Furthermore, we tested the non-competitive NMDA receptor antagonist MK-801 (dizolcipine), for which a positive effect on recovery after brain lesions is disputed. It has been suggested that MK801 might be able to act neuro-protectively (Grigg \& Anderson, 1990; Robinson \& Mair, 1992; Yanase et al., 1995), an action that may be due to decreases of secondary mechanisms affecting neuronal death, especially edema (Yanase et al., 1995) and calcium channel blocking (Schurr et al., 1995). Contradictory data exist, however, because Holtz \& Gerdin (1991) did not find any improvement of recovery with MK-801 treatment after spinal cord injury. Additionally, NMDA receptor imbalance has been reported after unilateral vestibular lesion ( $\mathrm{Li}$ et al., 1997); such imbalance could be reduced by MK- 801 treatment.

Thus, we tested the effects of post-operative treatment with SP, ACTH4-10, or MK-801 in the model of hemilabyrinthectomy in goldfish, with the expectation that SP and ACTH4-10 should promote recovery, whereas MK-801, if at all, should only weakly be effective. 

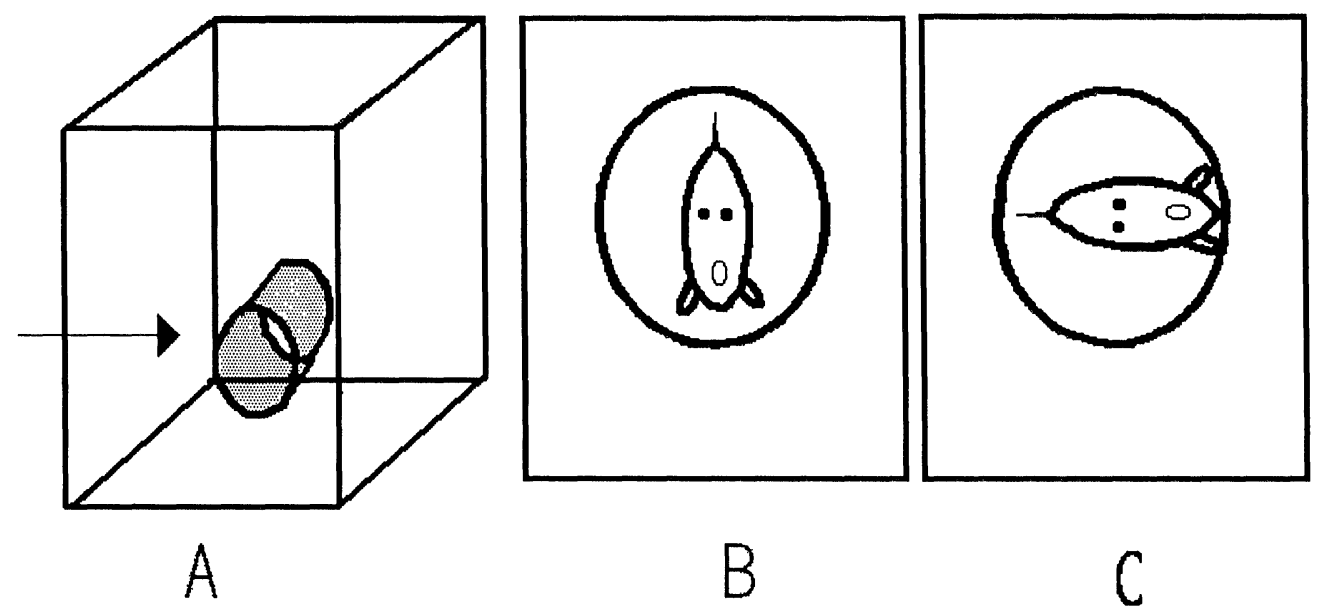

Fig. 1: A, Schematic representation of the testing chamber being illuminated from the right side. B, Fish represented with no tilt or $0^{\circ}$ and $\mathbf{C}$, fish represented with maximum tilt or $90^{\circ}$, as seen on TV screen.

\section{METHODS}

\section{Animals}

Fifty-eight unsexed, experimentally naive comet goldfish (Carassius auratus), weighing between 3.5 to $7.0 \mathrm{~g}$ each, were maintained in groups of 12 or less in continuously filtered and aerated $60-\mathrm{L}$ aquaria, under natural temperature and a light cycle of $14 \mathrm{~h}$ light/10 h dark. They were fed $5 \mathrm{~d}$ per week with goldfish pellets (Wardley, USA).

\section{Test chamber}

For the DLR test, a black aquarium $(15 \mathrm{~cm}$ high, $20 \mathrm{~cm}$ long, $10.5 \mathrm{~cm}$ wide) was placed in a small room that could be darkened completely. This aquarium had a small transparent window on the right side that allowed light to enter from a lamp placed at that side. Another transparent window at the front wall allowed video recording of the animals' behavior. Inside the aquarium, a translucent tube $(2.5 \mathrm{~cm}$ diameter) was attached to the front wall. The tube was used to keep the animal facing forward, allowing the fish to tilt, but not to turn away from the front wall (Fig. 1).

\section{Drugs and treatmensts}

Substance $\mathrm{P}$ acetate and ACTH4-10 (Sigma Chemical Co., St Louis, Missouri, USA); and MK801 (RBI, Natick, Massachusetts, USA) were dissolved in distilled water to concentrations of 25 $\mu \mathrm{g} / \mathrm{mL}$ (SP), $125 \mu \mathrm{g} / \mathrm{mL}$ (ACTH4-10), and $50 \mu \mathrm{g} / \mathrm{mL}$ (MK-801). All substances were placed immediately in a freezer $\left(-40^{\circ} \mathrm{C}\right)$ in aliquots of $250 \mu \mathrm{L}$. Fresh aliquots were thawed on each injection day. All substances were administered in a volume of 2 $\mathrm{mL} / \mathrm{kg}$ body weight using a $1-\mathrm{mL}$ syringe and a $27-$ gage needle. The final doses used were $50 \mu \mathrm{g} / \mathrm{kg}$ 
for SP, $250 \mu \mathrm{g} / \mathrm{kg}$ for ACTH4-10, and $100 \mu \mathrm{g} / \mathrm{kg}$ for MK-801. These doses were derived from previous studies (Flohr \& Lüneburg, 1982; Mattioli et al., $1995,1996 ; 1997)$. Because this was an initial study to examine the suitability of the goldfish hemilabyrinthectomy model for functional recovery rather than a study of drug efficacy, the dose response of the drugs were not evaluated. Vehicleinjected fish received distilled water of the same volume. The animals were injected $5 \mathrm{~d}$ per wk for 3 wk, beginning after the first DLR test, which was performed $24 \mathrm{~h}$ after surgery. Treatment was discontinued on day 20 , and two additional tests were performed, on days 22 and 24 after the lesion.

\section{Surgery}

Fish were anesthetized by placing them in a solution of tricaine methanesulphonate (TMS) $(0.6$ $\mathrm{g} / \mathrm{L}$ ) until gill movements stopped. The fish were then wrapped in wet gauze and placed on a stand that stabilized the body by laterally placed adjustable holders. Anesthesia and artificial ventilation were maintained by perfusing the animals through the mouth continuously with an aerated solution of TMS $(0.3 \mathrm{~g} / \mathrm{L})$.

A small triangular opening was cut in the skull just behind and above the right eye. The utricle was localized and gently pulled out; attached portions of the pars superior (e.g. semicircular canals) were also removed (Ott \& Platt, 1988a, 1988b). The space was then filled with sterile gel foam (Upjohn Co., Kalamazoo, Michigan, USA), and the skull hole was closed with dental acrylic (Motloid Co., Chicago, Illinois, USA). Little, if any, bleeding was observed during successful surgery. After the skull was closed, the anesthetic solution was replaced by fresh water until the fish began moving. The fish were then placed in the maintenance aquarium and were observed for immediate ataxia, a sign that was used to evaluate surgical success and served as a necessary condition for including the animal in the experiment.

Another group $(n=5)$ was anesthetized, the skull was opened and closed the same way; but without otolith removal. These animals did not differ in body tilt from seven other non-operated animals. Therefore, they were pooled with the nonoperated animals into one non-lesion, control group. Altogether, the following groups were tested:

- Group SP, $\mathrm{n}=11$, lesion and injected with Substance $\mathrm{P}(50 \mu \mathrm{g} / \mathrm{kg}$ body wt.),

- Group ACTH, $\mathrm{n}=12$, lesion and injected with ACTH4-10 (250 $\mu \mathrm{g} / \mathrm{kg}$ body wt.),

- Group MK, $\mathrm{n}=12$, lesion and injected with MK-801 (100 $\mu \mathrm{g} / \mathrm{kg}$ body wt.),

- Group VEH, $\mathrm{n}=12$, lesion and injected with vehicle ( $2 \mathrm{~mL} / \mathrm{kg}$ body wt.),

- Group NON, n=11, no-lesion, not injected.

\section{Testing procedure}

Twenty-four hours after surgery, the animals were placed in the experimental chamber, which was held at ambient room temperature $\left(24 \pm 2^{\circ} \mathrm{C}\right)$. Then, the room was completely darkened, and the light on the right side of the experimental chamber was turned on. The animals' behavior was recorded on videotape for $5 \mathrm{~min}$ with the recording time (in seconds) displayed on-screen at recording and videotape playback. This test was repeated on days $3,8,10,15,17,22$, and 24 after surgery. The tilt angle was determined after testing by stopping the tape during playback at each full minute, and by measuring the angle formed between a line traced through the eyes and a horizontal line. Five measures were taken from each animal per test, and the angle used for each day was the mean of these five measures.

\section{Statistical analysis}

A two-way analysis of variance (ANOVA) with repeated measures was made to determine 
whether a treatment regimen or postoperative time or an interaction between these factors affected tilt angles. For multiple comparisons between means, the Student-Newman-Keuls analysis was used; the significance level was established at 5\%.

\section{RESULTS}

After recovering from anesthesia, the labyrinthectomized animals showed immediate ataxia that lasted between 30 and $40 \mathrm{~min}$; a few animals that did not recover from this ataxia were not used further in the study. On the first test, performed on the first day after surgery and before any treatment was administered, the lesion groups showed a body tilt toward the light side of about 50 degrees, whereas the no-lesion control group had a tilt of about 7 degrees to the same side. The degree of tilt was significantly higher in the lesion groups than in the no-lesion group (Table 1).

Throughout the postoperative testing period, the statistical analysis of DRL (two-way ANOVA with repeated measures, Fig. 2) yielded significant differences between treatments $(\mathrm{F}=12.54, \mathrm{p}<0.0001)$, a significant effect of post-operative time $(\mathrm{F}=17.81$, $\mathrm{p}<0.0001$ ), and an interaction effect between treatments and time $(\mathrm{F}=2.39, \mathrm{p}=0.0001)$. Further multiple comparisons indicated that on the first day after surgery, the four hemilabyrithectomized groups (SP, ACTH, MK, VEH) differed from the no-lesion group (NON), whereas at $22 \mathrm{~d}$ after surgery, only the VEH group remained different from the no-lesion control group (Table 1).

\section{TABLE 1}

Means $( \pm$ S.E.M) of the body tilt on different test days after surgery

\begin{tabular}{cccccc} 
Days & Non & Vehicle & ACTH $_{4-14}$ & SP & MK-801 \\
\hline 1 & 7.17 & $48.55^{\dagger}$ & $52.00^{\dagger}$ & $49.10^{\dagger}$ & $47.53^{\dagger}$ \\
& $( \pm 1.99)$ & $( \pm 7.36)$ & $( \pm 8.24)$ & $( \pm 7.64)$ & $( \pm 7.41)$ \\
\hline 3 & 8.91 & $46.67^{\dagger}$ & $31.39^{\ddagger}$ & $37.33^{\dagger}$ & 30.60 \\
& $( \pm 1.65)$ & $( \pm 7.27)$ & $( \pm 3.37)$ & $( \pm 8.73)$ & $( \pm 5.13)$ \\
\hline 8 & 8.50 & $49.14^{\dagger}$ & $30.09^{\ddagger}$ & $29.27^{\ddagger}$ & 33.57 \\
& $( \pm 1.86)$ & $( \pm 6.87)$ & $( \pm 4.55)$ & $( \pm 8.14)$ & $( \pm 6.81)$ \\
\hline 10 & 9.42 & $41.97^{\dagger}$ & $26.31^{\ddagger}$ & $29.27^{\ddagger}$ & $11.50^{\ddagger}$ \\
& $( \pm 1.77)$ & $( \pm 5.80)$ & $( \pm 3.59)$ & $( \pm 8.31)$ & $( \pm 2.06)$ \\
\hline 15 & 7.83 & $35.66^{\dagger}$ & $15.28^{\ddagger}$ & $28.85^{\ddagger}$ & $16.43^{\ddagger}$ \\
& $( \pm 1.56)$ & $( \pm 7.22)$ & $( \pm 2.31)$ & $( \pm 5.14)$ & $( \pm 2.05)$ \\
\hline 17 & 8.74 & $45.13^{\dagger}$ & $18.80^{\ddagger}$ & $21.81^{\ddagger}$ & $15.63^{\ddagger}$ \\
& $( \pm 2.20)$ & $( \pm 8.52)$ & $( \pm 3.03)$ & $( \pm 4.93)$ & $( \pm 3.25)$ \\
\hline 22 & 5.17 & $34.78^{\dagger}$ & $14.41^{\ddagger}$ & $17.43^{\ddagger}$ & $14.18^{\ddagger}$ \\
& $( \pm 2.07)$ & $( \pm 9.20)$ & $( \pm 2.72)$ & $( \pm 2.82)$ & $( \pm 3.33)$ \\
\hline 24 & 5.90 & 29.35 & $16.18^{\ddagger}$ & $14.09^{\ddagger}$ & $15.13^{\ddagger}$ \\
& $( \pm 2.22)$ & $( \pm 7.15)$ & $( \pm 3.17)$ & $( \pm 3.45)$ & $( \pm 1.57)$ \\
\hline
\end{tabular}

${ }^{\dagger} \mathrm{p}<0.05$ Student-Newman-Keuls multiple comparison test group versus non group.

${ }_{\mathrm{p}}^{ \pm}<0.05$ Student-Newman-Keuls multiple comparison test, day versus first day after surgery. 


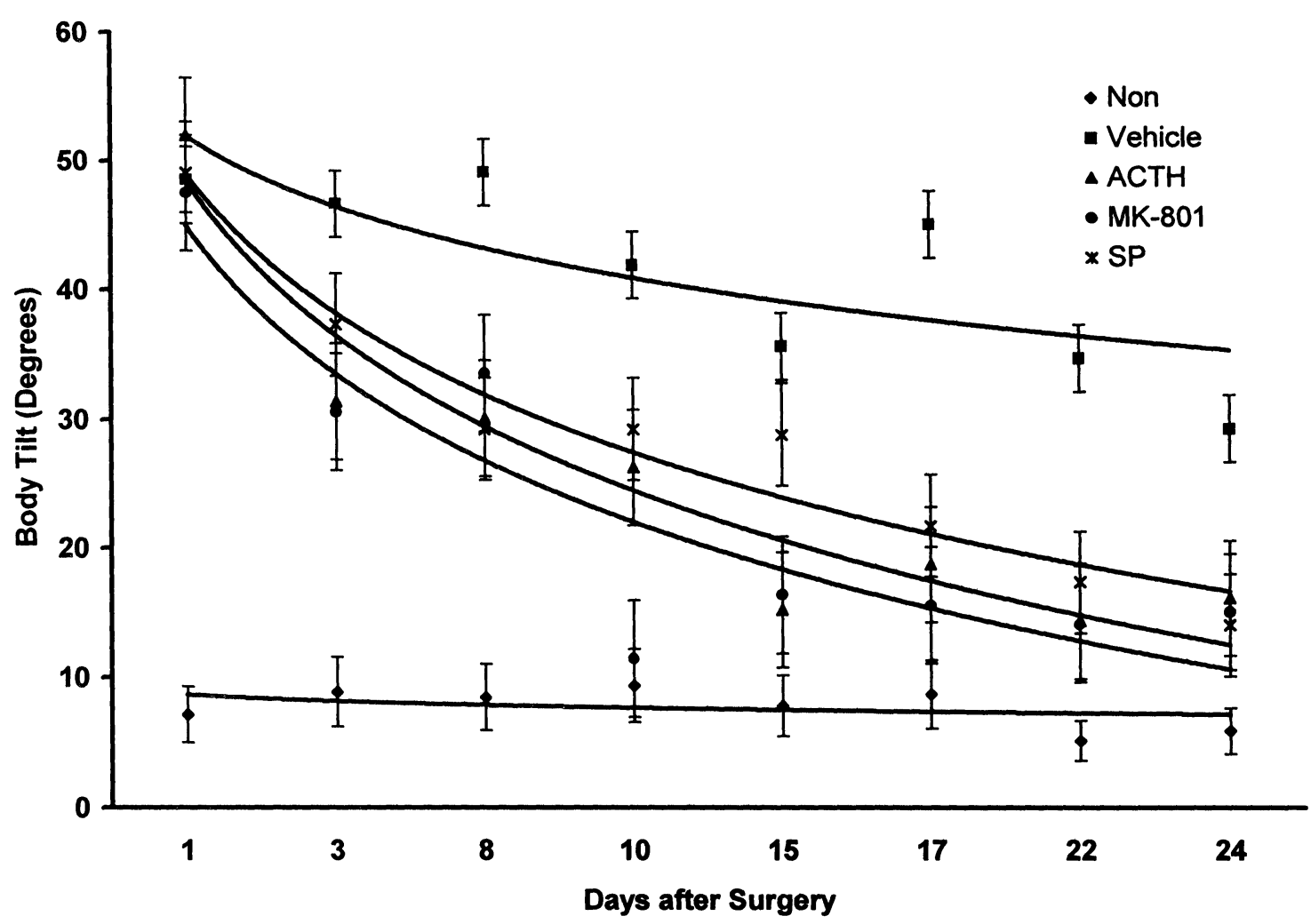

Fig. 2: Means ( \pm S.E.M) of the body tilt of goldfish after unilateral lesion of the labyrinth. Logarithmic trend-lines were added for visualization purposes only. The trend-lines, from top to bottom represent the best fitting curve for the results of the NON, VEH, ACTH, MK and SP groups respectively.

Within-group comparisons showed no difference between days in the lesion group treated with vehicle (VEH) and in the non-lesion group (NON; Table 1). The results of DLR testing after treatment indicate that the degree of body tilt significantly recovered by the $3^{\text {rd }}$ day for the group treated with ACTH4-10, by the $8^{\text {th }}$ day for the group treated with SP, and by the $10^{\text {th }}$ day for the group treated with MK-801. The within-group comparison did not indicate a significant recovery of body tilt in the lesion-group treated with vehicle until the last day of testing, when the degree of tilt no longer differed from that of the no-lesion control.

After this experiment, we found in vitro evidence suggesting a suppression of optic field potentials by MK-801 in goldfish (van Deusen \& Meyer, 1990). To test a possible effect of MK-801 on the visual system of goldfish, we tested nolesion animals for DLR after chronic treatment with MK-801 for $10 \mathrm{~d}$. The results of these animals did not differ from those of non-lesioned, vehicle-treated animals (Mann Whitney U-test, $\mathrm{p}=0.0997$; Vehicle: 12.1 $\pm 2.18, \mathrm{MK}-801: 17.6 \pm 2.95$; mean \pm SEM). 


\section{DISCUSSION}

This study shows that hemilabyrinthectomy in goldfish is suitable for analyzing lesion-induced functional deficits and the effectiveness of drug treatments to improve recovery therefrom. The method used to lesion the labyrinth was the removal of the right utricle and remaining pars superior. The difference between lesion and nolesion animals in tilt on the first day after surgery confirms that pars superior removal results in a measurable postural imbalance, and that the DLR test is suitable for detecting postural deficits after hemilabyrinthectomy in goldfish, as proposed by Ott and Platt (1988a, 1988b). Curiously, Ott and Platt reported substantially lower tilt angles 1-day post-hemilabyrinthectomy than those noted in this study (mean $19.2^{\circ}$ versus $48.6^{\circ}$ ). The reason for this difference is not clear but is presumably due to some methodological differences between the two studies (namely, light levels in the test apparatus) and warrants further study.

The results with the three drug treatments in this study indicate that not only the neuropeptides SP and ACTH4-10 but also the NMDA receptor blocker MK-801 accelerated functional recovery of body tilt induced by DLR in the goldfish model of hemilabyrinthectomy. The absence of rebound increase in body tilt on the tests performed after the termination of drug treatments indicates that the postural improvement was not due to a temporary drug effect but may have occurred through a process of reorganization.

The two neuropeptides tested, that is, SP and ACTH4-10, have previously been shown to improve functional recovery in different lesion models and species (Flohr \& Lüneburg, 1982; Igarashi et al., 1985; Mattioli et al., 1992; Antonawich et al., 1993; Bannon et al., 1995; Sprick et al., 1996). Such promotive effects might be due to their known neurotrophic effects (Jonsson \& Hallman, 1982; Nyakas et al., 1985; van der Neut et al., 1988; Iwasaki et al., 1989; Kowall et al., 1991). Nevertheless, neuronal regeneration usually takes weeks to months to occur (Antonawich et al., 1993; Zottoli et al., 1994; for review see Marshall, 1985); therefore, such a mechanism is rather unlikely to have been critical in the present experiment because the peptidergic treatments led to functional recovery within days. Alternatively, they may have acted neurochemically by inducing short term changes that compensated for the lesion-induced loss; in this case, however, cessation of drug treatment should have led to a reappearence of deficits (Flohr \& Lüneburg, 1982), which did not occur, at least during the subsequent 4 days.

Because functional recovery after lesion is also dependent on the organism's ability to relearn or to compensate behaviorally (Morgan et al., 1983; Mattioli et al., 1988), the role of learning and behavioral compensation must be considered as alternative or additive factors. Both SP and ACTH have been shown to promote learning and memory (Greven \& de Wied, 1973; de Wied \& Gispen, 1977; Stäubli \& Huston, 1980; Wetzel \& Matthies, 1982; Tomaz \& Huston, 1986; Tomaz et al., 1990; Wan et al., 1992; Huston \& Hasenöhrl, 1995; Mattioli et al., 1997), and to have reinforcing effects in rats and goldfish (Huston \& Oitzl, 1989; Oitzl et al., 1990; Huston \& Hasenöhrl, 1995; Mattioli et al., 1995; 1996), and such effects may facilitate functional recovery, for example, by improving behavioral compensation and re-learning. Effects on learning might also explain why the peptides acted rather rapidly and why their effectiveness outlasted drug discontinuation.

From such a learning hypothesis, one should have expected that the NMDA receptor antagonist MK-801 should not promote recovery because this drug is known to impair learning and memory in several paradigms (Xu \& Davies, 1992; Buffalo et al., 1994; Caramanos \& Shapiro, 1994; Davis \& Klinger, 1994; Paule, 1994; Filliat \& Blanchet, 1995; Hudzik \& Palmer, 1995; Kesner \& Dakis, 
1995; Mele et al., 1995; Ylinen et al., 1995; Verma \& Moghaddam, 1996). Our results, however, indicate that MK-801 actually improves functional recovery. Apparently, the drug's action on recovery is dependent on a mechanism other than learning. Possibly, MK-801 acted neuroprotectively (Grigg \& Anderson, 1990; Robinson \& Mair, 1992; Yanase et al., 1995). In the case of hemilabyrinthectomy, a neuroprotective action cannot be ruled out because the removal of the labyrinth can lead to retrograde central degeneration after disruption of the $8^{\text {th }}$ cranial nerve, against which MK-801 might have acted neuroprotectively.

Alternatively, it could be argued that MK-801 did not act in a protective or promotive fashion but rather neurotoxically, for example on the visual system (van Deusen \& Meyer, 1990). Such an action could reduce the animal's ability to react to the luminous stimulus, which would then lead to a reduction in DLR. This was probably not the case in the present study, however, because the animals treated with MK-801 presented a stronger body tilt than did non-operated controls. Furthermore, we tested non-lesion animals, treated chronically with MK-801, and that we could not detect a difference in DLR between treated and untreated animals, indicates that the systemic injections of MK-801, at the dose used in this experiment, seem not to be neurotoxic on the visual system (not shown).

The present MK-801-induced facilitation of functional recovery contrasts with previously reported data (Flohr \& Lüneburg, 1993), in which MK-801 treatment resulted in an inhibition of the initial phases of recovery in goldfish and frogs. Such different results might reflect important dose dependencies because the former authors administered comparatively high dosages, that is, 0.5 and $2.0 \mathrm{mg} / \mathrm{kg}$, whereas we used $100 \mu \mathrm{g} / \mathrm{kg}$. Furthermore, it might be possible that even a low dose of MK-801 might disturb behavioral compensation acutely after injection (Kim et al., 1997), whereas such an effect is no longer present after
$24 \mathrm{~h}$, the timepoint at which we measured the animal's behavior.

In a recent review (de Waele, 1995), the complex neurochemistry of the vestibular system was summarized. In addition to SP, ACTH, and glutamate, this system has neurons containing somatostatin, enkephaline, GABA, glycine, acetylcholine, noradrenaline, dopamine, serotonine, and histamine; more than 21 receptor types are present. Examining the full range of agonists and antagonists of these receptors on functional recovery is still an incomplete task. The model used in the present study is one of the tools that can help to dissect the vestibular system pharmacologically, as well as, the functional recovery processes after vestibular lesions.

In conclusion, the results of this study show that measuring the dorsal light reflex in the goldfish model of hemilabyrinthectomy provides a suitable approach to studying the effectiveness of drug treatments to promote functional recovery. The data presented here might stimulate further research, for example to investigate other potential drug treatments, like growth factors, or to determine physiological variables that are critical for drugpromoted recovery.

\section{ACKOWLEDGMENT}

This study was supported by grant $95 / 4337-0$ from FAPESP, Brazil, and by grant (Hu 306/13-1) from the Deutsche Forschungsgemeinschaft

\section{REFERENCES}

Antonawich FJ, Azmitia EC, Strand FL. Rapid neurotrophic action of an ACTH/MSH(4-9) analogue after nigrostriatal 6-OHDA lesioning. Peptides 1993; 14: 1317-1324.

Bannon MJ, Brwonschidle LA, Tian Y, Whitty CJ, Poosch MS, D'sa C, Moody CA. Neurokinin-3 
modulate dopamine cell function and alters the effects of 6-hydroxydopamine. Brain Res 1995; 695: 19-24.

Bienhold H, Flohr H. Role of cholinergic synapses in vestibular compensation. Brain Res 1980; 195: 476-478.

Buffalo EA, Gillam MP, Allen RR, Paule MG. Acute behavioral effects of MK-801 in rhesus monkeys: assessment using an operant test battery. Pharmacol Biochem Behav 1994; 48: 935-940.

Caramanos Z, Shapiro ML. Spatial Memory and Nmethyl-D-aspartate receptor antagonists APV and MK-801: Memory impairments depend on familiarity with the environment, drug dose, and training duration. Behav Neurosci 1994; 108: 30 43.

Davis RE, Klinger PD. NMDA receptor antagonist MK-801 blocks learning of conditioned stimulusunconditioned stimulus contiguity but not fear of conditioned stimulus in goldfish (Carassius auratus L.). Behav Neurosci 1994; 108: 935-940.

Deliagina T. Vestibular compensation in lampreys: role of vision at different stages of recovery of equilibrium control. J Exp Biol 1997; 23: 29572967.

De Waele C, Muehlenthaler M, Vidal PP. Neurochemistry of the central vestibular pathways. Brain Res Rev 1995; 20: 24-46.

De Wied D, Gispen WH. Behavioral effects of peptides. In: Gainer H, ed, Peptides in neurobiology. New York, NY, USA: Plenum Press, 1977; 397-448.

Dieringer N. 'Vestibular compensation': Neural plasticity and its relations to functional recovery after labyrinthine lesions in frogs and other vertebrates. Prog Neurobiol 1995; 46: 97-129.

Dieringer N, Precht W. Mechanisms of compensation for vestibular deficits in the frog: II. Modification of the inhibitory pathways. Exp Brain Res 1979; 36: 329-341.

Filliat P, Blanchet G. Effects of TCP on spatial memory: Comparison with MK-801. Pharmacol Biochem Behav 1995; 51: 429-434.

Flohr H, Lüneburg U. Effects of ACTH4-10 on vestibular compensation. Brain Res 1982; 248: 169-173.

Flohr H, Lüneburg U. Role of NMDA receptors in lesion-induced plasticity. Archieves Italiennes de Biologie 1993; 131: 173-190.

Flohr H, Bienhold WA, Macskovics I. Concepts of vestibular compensation. In: Flohr $\mathrm{H}$, Precht $\mathrm{W}$, eds, Lesion-induced neuronal plasticity in sensorimotor systems. Berlin, Germany: Springer Verlag, $1981 ; 153-172$.

Greven HM, de Wied D. The influence of peptides derived from corticotrophin (ACTH) on performance. Structure-activity studies. Progr Brain Res 1973; 39: 429-442.

Grigg JJ, Anderson EG. Competitive and noncompetitive N-methyl-D-aspartate antagonists modify hypoxia-induced membrane potential changes and protect rat hippocampal slices from functional failure: A quantitative comparison. $\mathrm{J}$ Pharmacol. Exp. Ther. 1990; 253: 130-135.

Holtz A, Gerdin B. MK 801, an OBS N-methyl-Daspartate channel blocker, does not improve the functional recovery nor spinal cord blood flow after spinal cord compression in rats. Acta Neurol Scand 1991; 84: 334-338.

Hudzik TJ, Palmer GC. Effects of anticonvulsants in a novel operant learning paradigm in rats: Comparison of remacemide hydrochloride and FPL 15896AR to other anticonvulsant agents. Epilepsy Res 1995; 21: 183-193.

Huston JP, Hasenöhrl RU. The role of neuropeptides in learning: focus on the neurokinin substance P. Behav Brain Res 1995; 66: 117-127.

Huston JP, Oitzl MS. The relationship between reinforcement and memory: Parallels in the rewarding and mnemonic effects of the neuropeptide substance P. Neurosci Biobehav Rev 1989; 13: 171-180.

Igarashi $\mathrm{M}$, Ishikawa $\mathrm{K}$, Ishii $\mathrm{M}$, Schmidt $\mathrm{KA}$. Effect of ACTH-(4-10) on equilibrium compensation after unilateral labyrinthectomy in the squirrel monkey Eur J Pharmacol 1985; 119: 239-242.

Iwasaki Y, Kinoshita M, Ikeda K, Takamiya K, Shiojima T. Trophic effect of various neuropeptides on the cultured ventral spinal cord of rat embryo. Neurosci Lett 1989; 101: 316-320.

Jonsson G, Hallman H. Substance P counteracts neurotoxin damage on norepinephrine neurons in rat brain during ontogeny. Science 1982; 215 : 75 77.

Kesner RP, Dakis M. Phencyclidine injections into the dorsal hippocampus disrupt long- but not shortterm memory within a spatial learning task. Psychopharmacology, 1995; 120: 203-208.

Kim MS, Jin BK, Chun SW, Lee MY, Lee SH, Kim JH, Park BR. Role of vestibular N-Methyl-D- 
aspartate receptors for behavioral recovery following unilateral labyrinthectomy in rats. Neurosci Lett 1997; 222: 171-174.

Kowall NW, Beal MF, Busciglio J, Duffy LK, Yankner BA. An in vivo model for the neurodegenerative effects of amyloid and protection by substance $P$. Proc Natl Acad Sci USA 1991; 88: 7247-7251.

Li H, Godfrey DA, Rubin A M. Quantitative autoradiography of $5-\left[{ }^{3} \mathrm{H}\right]$ dizicilpine maleate binding in rat vestibular nuclear complex after unilateral deafferentation, with comparison to cochlear nucleus. Neuroscience 1997; 77: 473-484.

Marshall JF. Neuronal plasticity and recovery of function after brain injury. Int Rev Neurobiol 1985; 26: 201-247.

Mattioli R, Bueno JLO, Tomaz C. Conditioned turning and functional recovery after unilateral substantia nigra lesion in rats. Brazilian $\mathrm{J}$ Med Biol Res 1988; 21: 655-658.

Mattioli R, Schwarting RKW, Huston JP. Recovery from unilateral 6-hydroxidopamine lesion of substantia nigra promoted by the neurotachykinin substance P 1-11. Neuroscience 1992; 48: 595-605.

Mattioli R, Aguilar C, Vasconcelos L. Reinforcing properties of the neuropeptide substance $P$ in Carassius auratus: evidence of dopaminergic system involvement. Pharmacol Biochem Behav 1995; 50: 77-81.

Mattioli R, Coelho J, Martins A. Reinforcing properties of the substance P C-fragment analog DiMe-C7 in Carassius auratus. Brazilian J Med Biol Res 1996; 29: 495-499.

Mattioli R, Santangelo EM, Costa AA, Vasconcelos L. Substance $\mathbf{P}$ facilitates memory in goldfish in an appetitively motivated learning task. Behav Brain Res 1997; 85: 117-120.

Mele A, Castellano C, Oliverio A. Chronic treatment with MK-801 affects the behavioral response to both D1 and D2 dopamine agonist in the one trial inhibitory avoidance. Psychopharmacology 1995; 121: 401-405.

Morgan S, Huston JP, Pritzel M. Effects of reducing sensory-motor feedback on the appearance of crossed nigro-thalamic projections and recovery from turning induced by unilateral substantia nigra lesions. Brain Res Bull 1983; 11: 721-727.

Nikolaus S, Huston JP, Schwarting RKW. Pretreatment with fragments of Substance $P$ or with Cholecystokinin differentially affects recovery from sub-total nigrostriatal 6-hydroxidopamine lesion.
Neural Plast 1999; 6: 77-89.

Nyakas C, Veldhuis HD, De Wied D. Beneficial effect of chronic treatment with Org 2766 and -MSH on impaired reversal learning of rats with bilateral lesions of the parafascicular area. Brain Res Bull 1985; 15: 257-265.

Oitzl MS, Hasenöhrl RU, Huston JP. Reinforcing effects of peripherally administered substance $P$ and its C-terminal pGlu6-SP6-11 in the rat. Psychopharmacology 1990; 100: 308-315.

Ott JT, Platt C. Early abrupt recovery from ataxia during vestibular compensation in goldfish. J Exp Biol 1988a; 138: 345-357.

Ott JT, Platt C. Postural changes occurring during one month of vestibular compensation in goldfish. $\mathrm{J}$ Exp Biol 1988b; 138: 359-374.

Paule MG. Acute behavioral toxicity of MK-801 and phencyclidine: Effects on rhesus monkey performance in an operant test battery. Psychopharmacol Bull 1994; 30: 613-621.

Robinson JK, Mair RG. MK-801 prevents brain lesions and delayed-nonmatching-to-sample deficits produced by pyritiamine-induced encephalopathy in rats. Behav Neurosci 1992; 106: 623-633.

Sans N, Sans A, Raymond J Regulation of NMDA receptor subunit mRNA expression in the guinea pig vestibular nuclei following unilateral labyrinthectomy. Eur J Neurosci 1997; 9: 2019-2034.

Schaefer KP, Meyer DL. Compensation of vestibular lesions. In: Kornhuber HH, ed, Vestibular system: Psychophysics, Applied Aspects and General Interpretations; Handbook of Sensory Physiology, vol 4. New York, NY, USA: Springer Verlag, 1974; 463-490.

Schurr A, Payne RS, Rigor BM. Synergism between diltiazem and MK-801 but not APV in protecting hippocampal slices against hypoxic damage. Brain Res 1995; 684: 233-236.

Sprick U, Hasenöhrl RU, Krauth J, Klapdor K, Huston JP. Effects of chronic Substance P treatment and intracranial fetal grafts on learning after hippocampal kainic acid lesions. Peptides 1996; 17: 275-285.

Stäubli U, Huston JP. Facilitation of learning by posttrial injection of substance $P$ into the medial septal nucleus. Behav Brain Res 1980; 1: 245-255.

Tomaz C, Huston JP. Facilitation of conditioned inhibitory avoidance by post-trial peripheral injection of substance P. Pharmacol Biochem Behav 1986; 25: 469-472. 
Tomaz C, Aguiar MS, Nogueira PJC. Facilitation of memory by peripheral administration of substance $P$ and naloxone using avoidance and habituation learning tasks. Neurosci Biobehav Rev 1990; 14: 447-453.

Van Deusen EB, Meyer RL. Pharmacologic evidence for NMDA, APB and kainate/quisqualate retinotectal transmission in the isolated whole tectum of goldfish. Brain Res 1990; 536: 86-96.

Van Der Neut R, Bär PR, Sodaar P, Gispen WH. Trophic influences of alpha-MSH and ACTH4-10 on neuronal outgrowth in vitro. Peptides 1988; 9: 1015-1020.

Van Rijzingen IMS, Gipsen W-H, Spruijt BM. The ACTH(4-9) analog ORG 2766 and recovery after brain damage in animal models-a review. Behav Brain Res 1996; 74: 1-15.

Verma A, Moghaddam B. NMDA receptor antagonists impair prefrontal cortex function as assessed via spatial delayed alternation performance in rats: modulation by dopamine. J Neurosci 1996; 16: 373-379.

Vidal $P$, de Waele $C$, Vibert $N$, Muhlethaler $M$. Vestibular compensation revisited. Otolaryngol Head Neck Surg 1998; 119: 34-42.

Wan R, Diamant $\mathrm{M}$, de Jong $\mathrm{W}$, de Wied $\mathrm{D}$.
Differential effects of ACTH4-10, DG-AVP, and DG-OXT on heart rate and passive avoidance behavior in rats. Physiol Behav 1992; 51: 507513.

Wetzel W, Matthies H. Effect of substance P on the retention of a brightness discrimination task in rats. Acta Biol Med Germ 1982; 41: 647-952.

$\mathrm{Xu} \mathrm{X}$, Davies RE. N-methyl-D-aspartate receptor antagonist MK-801 impairs learning but not memory fixation or expression of classical fear conditioning in goldfish (Carassius auratus). Behav Neurosci 1992; 106: 307-314.

Yanase M, Sakou T, Fukuda T. Role of N-methyl-Daspartate receptor in acute spinal cord injury. $\mathrm{J}$ Neurosurg 1995; 83: 884-888.

Ylinen A, Pitkanen M, Sirvio J, Hartikainen T, Sivenius J, Koivisto E, Riekkinen PJ Sr. The effects of NMDA receptor antagonists at anticonvulsive doses on the performance of rats in the water maze task. Eur J Pharmacol 1995; 274 : 159-165.

Zottoli SJ, Bentley AP, Feiner DG, Hering JR, Prendergast BJ, Rieff HI. Spinal cord regeneration in adult goldfish: Implications for functional recovery in vertebrates. Prog Brain Res 1994; 103: 219-228. 

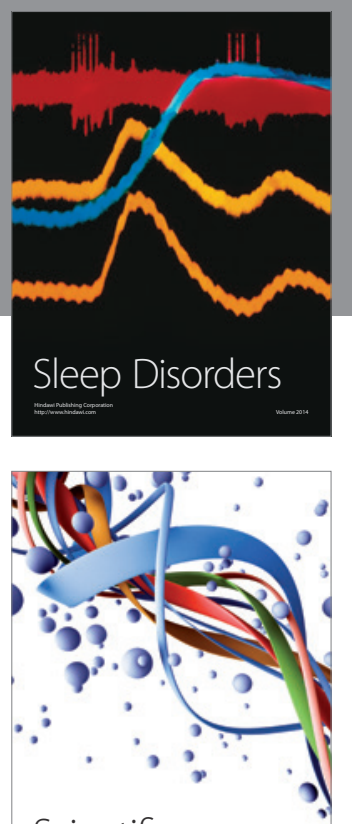

Scientifica
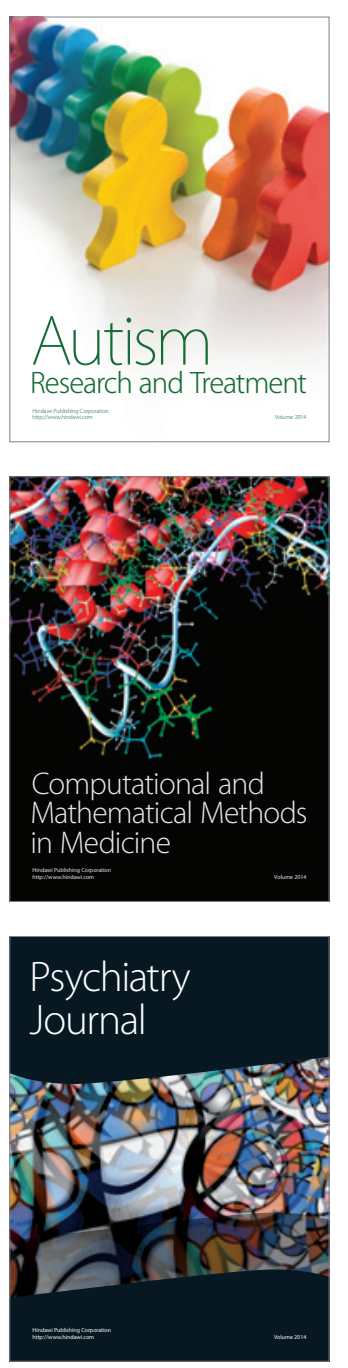
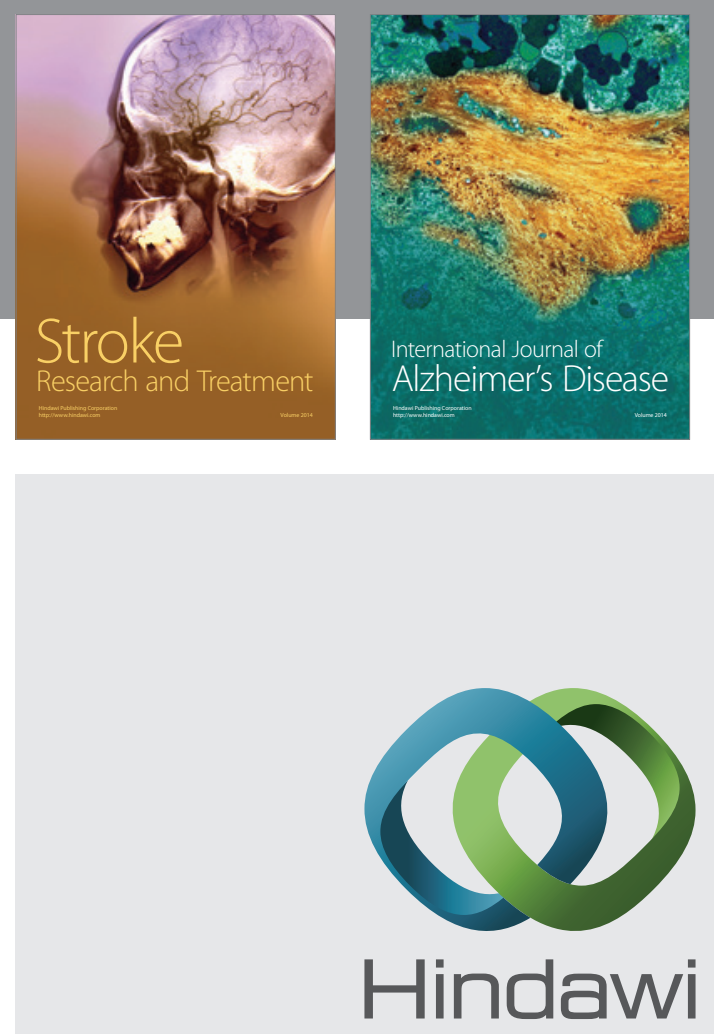

Submit your manuscripts at

http://www.hindawi.com
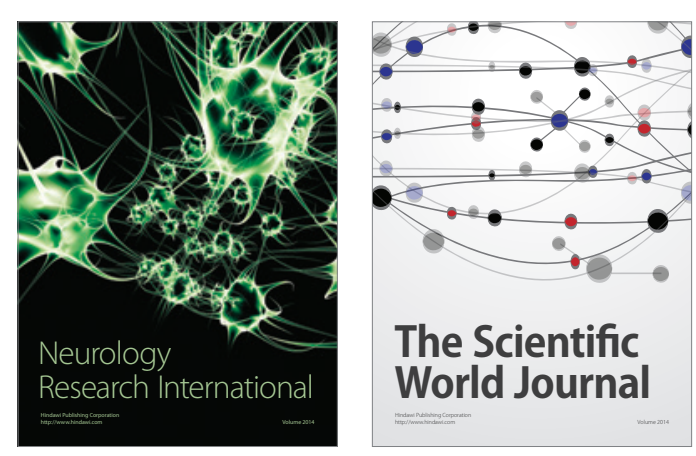

The Scientific World Journal

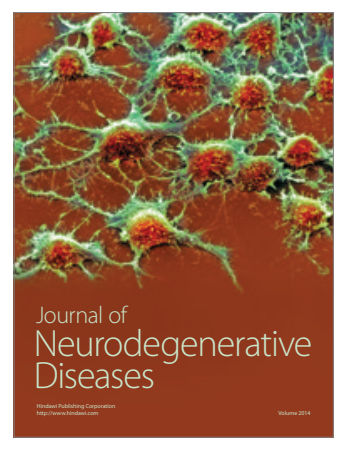

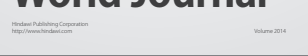

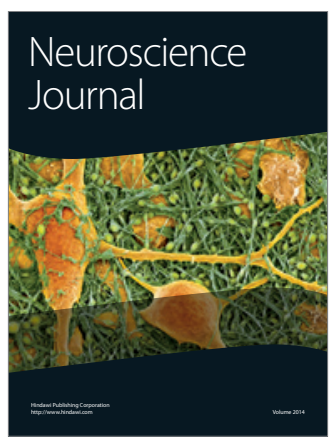

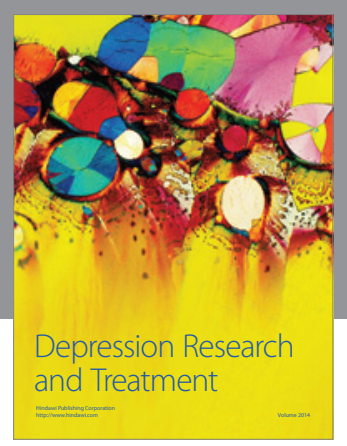
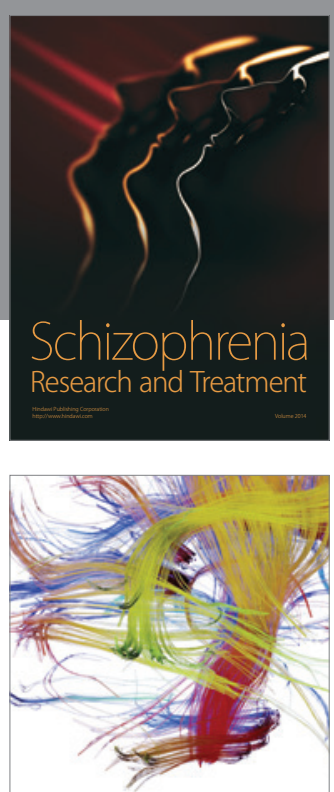

Brain Science

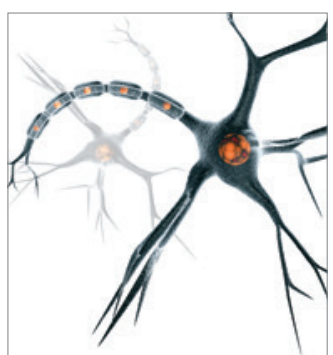

Neural Plasticity
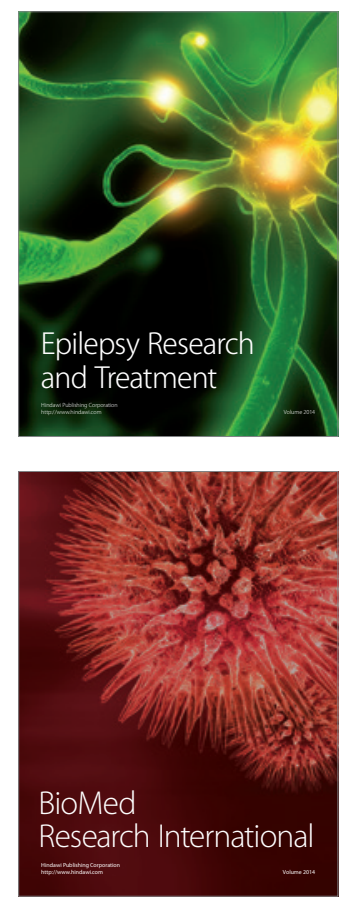

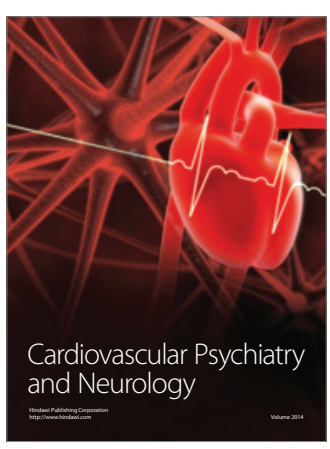

Parkinson's

Disease
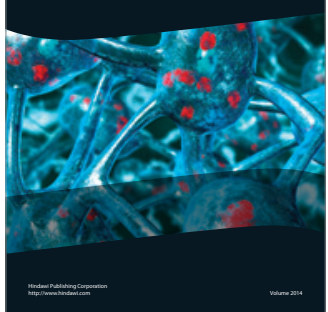